\title{
Exploring challenges in implementation of Learner-centered Approach in Pakistani EFL Classrooms
}

\author{
Mahenoor Ansari \\ MS Scholar, Mehran University of Engineering \& Technology, Jamshoro \\ Rosy Ilyas \\ Assistant professor, Mehran University of Engineering \& Technology, Jamshoro \\ Syed Waqar Ali Shah \\ Lecturer, Mehran University of Engineering \& Technology, Jamshoro
}

\begin{abstract}
This research focuses on the challenges that teachers confront in EFL classrooms at private secondary schools in Hyderabad, Pakistan. The study employs a qualitative research design conducted at five private secondary schools in Hyderabad, Pakistan. Classroom observations and semi-structured interviews are used to obtain data. Five EFL teachers were observed while teaching English in the classroom, and three of them were interviewed. Purposive sampling was used in this investigation. Thematic analysis is used to examine the data. It was discovered that teachers encounter challenges as a result of huge classrooms, a lack of resources, and approaches that have previously been provided to them.
\end{abstract}

Keywords: Difficulties, EFL teachers, Learner-centered approach, EFL classrooms

DOI: $10.7176 /$ JLLL/81-07

Publication date:September $30^{\text {th }} 2021$

\section{Introduction}

The classroom is where pupils learn several abilities that are thought to be necessary for learning and academic success. When students first go into the classroom, they make assumptions about the type of class they will be in. The unstated and unwritten assumptions about each other's attitudes and behaviors are referred to as classroom culture. 'A classroom gives us insight into teachers' and students' attitudes, expectations, and behaviors,' (Tudor 1996). Education allows students to think in all aspects by equipping them with the necessary knowledge, skills, and attitudes to invigorate their problem-solving talents. To attain them, students should be taught in a way that allows them to actively participate in the learning process. Teaching and learning procedures are two of the most crucial activities for teachers and students in educational environments. In order for a student to become an engaged learner, the teacher plays an important role (Ronald and David, 2001). In addition, depending on the educational level, there are two broad approaches of instruction that are used (i.e., Elementary, secondary, tertiary). Teachers-centered and learner-centered strategies are the two approaches. Teachers are in charge of all activities in the classroom in the teacher-centered method, students' attention is moved to the teacher because she is the major source of information for the students. Aside from that, a learner-centered approach allows students to concentrate on their knowledge and assist one another in solving issues. Learnercentered approaches give learners liberty and make them responsible for their own learning in the beginning.

\subsection{Research problem}

In Pakistani schools, traditional teaching methods are still maintained, not allowing teachers to use new and innovative approaches to learning from school authorities. According to Nyerere (1967), education should be used to develop human resources so that society becomes more conscious of the need for change. A new paradigm shift from old to current ways is being applied to improve the quality of teaching and learning. Teachers are unable to implement a learner-centered approach in the classroom because they are not permitted by higher administrations because it does not assist them in completing a topic, reduced class time, students are uninterested, and students do not select materials that support their learning process are some major issues faced 
by EFL teachers. The current study examines existing pedagogies at private schools in Hyderabad, Sindh, Pakistan. In order to identify challenges in implementing learner-centered approaches.

\subsection{Research Question}

The current study is supposed to address following question:

Q1. What are the difficulties that teacher face while implementing learner-centered approach in EFL classroom at private secondary schools in Hyderabad Pakistan?

\section{Literature review}

A learner-centered approach is an umbrella term that describes efforts on the part of students to become active learners and on the part of teachers to provide materials that support their learning. 2017 (Hoidn). However. In terms of classroom methods, a student-centered approach emphasizes students' inventions, creativity, and cooperation in their learning. The ability of students to analyze and evaluate their higher-level thinking is known as active learning (Ott et al.2018).

According to Tani (2005), students in Asian countries prefer to be silent during the teaching and learning process because they are afraid of making mistakes. The "culture of silence" is also becoming thicker as a result of teacher evaluations that are just black and white/wrong or right when it comes to pupils. As a result, students have a low level of engagement in the teaching and learning process, and they are well positioned as "know receiver" in the classroom, making them less critical thinkers. There is also a culture that develops good student characteristics as a result of teacher-centered learning.

The premise behind the application of the Learner-Centered Approach is a little more problematic because of its traditions, fallacies, pedagogy, and availability of student-centered learning contexts. Some members of an institution's faculty or staff have expressed reservations about whether this technique will improve students' responsibility for involvement and encourage them to participate in the learning process (Harju and Akerblom, 2017). The lecture method is still the most popular. Most teachers opt to conduct lectures for a variety of reasons, including completing course content due to the large number of students in one session, introducing new knowledge, and so on. EFL teachers are also known to prefer giving lectures because they enjoy talking, and they are less concerned with how much learning is taking place in the classroom. It's also due to teachers' mindsets, which believe that learner-centered is time-consuming and will not assist them in completing duties, thus they end up talking in the classrooms without participating actively as noted by Mezar and Hess (2017).

Tadesse et al (2021) conducted a research study in African context on instructors' perspectives on learnercentered pedagogy where they also discussed the hurdles to be implementing a learner-centered strategy, they discovered that teachers are opposed to this method for a variety of reasons. Traditional teaching tactics, for example, are still more concentrated and dominant than innovative approaches since administrators have previously directed them to adopt such strategies in the classroom. They found that classes were over loaded students. Guidance about teaching methods were instructed to teachers prior the lectures, unavailability of resources, fixed seating arrangements etc. Teachers were unable to make group activities therefore learnercentered activities are not possible to implement. Furthermore, the researcher found that teachers are also not capable enough in English language that is why they also were reluctant to talk in English language in EFL classes.

Mina and Zohreh (2015) researched on 'Iranian English teachers' beliefs about teacher centered education vs their beliefs about actual classroom roles. The study explored the challenges that were faced by teacher of Lundazi district. Findings of the research study shows that teachers are motivated to employ alternative teaching methods, however their real duty as educators contradicts their views. Because of the constraints placed on Iranian teachers, they are forced to rely on teacher-centered activities such as course completion. The majority of African teachers teach English to their students in order for them to pass their exams.

Akhtar et al (2018) researched on Mathematics Elementary School Teachers' Perceptions of the StudentCentered Approaches and Professional Learning Experiences and difficulties in using these approaches. Teachers had difficulty applying this technique in mathematics classrooms due to a lack of resources and availability, as well as the large class size. In Pakistan, there is also a lack of educational funding, making things much more challenging. Furthermore, there are no teacher training institutes in Pakistan where these ideas can be taught and practiced. Semi-structured interviews and Chi-square tests were utilized to collect data from both male and female teachers in this study. This investigation yielded both favorable and unfavorable results. Some teachers claimed that they do not have enough time in the classroom to execute a learner-centered approach 
because mathematics is a subject that should be understood by all students. Teacher cannot abandon any learner without ensuring that they comprehend the issue. Understanding and dealing with this subject takes a long time. They also performed a chi-square test, and many female teachers agreed that utilizing a learner-centered approach creates a calm and stress-free environment for students, allowing them to finish their duties without feeling rushed or burdened.

Elize (2020) conducted a study on teacher's perceptions, experiences and challenges regarding learner-centered teaching. This study included fourth-year B.Ed. students. According to the findings, both teachers and students had a limited understanding of learner-centered teaching and faced issues such a lack of expertise and experience in learner-centered teaching, as well as a negative impact due to overcrowding and poor classroom management. When a class has a large number of students, the mumbling becomes louder, and everyone has to shout in order to convey their message.

\section{Research methodology}

This study has used qualitative research method. As Denzin \& Lincoln (2008) maintains that qualitative research tries to provide a mechanism for the researcher to understand a phenomenon by seeing or interacting with the study's participants. The data is gathered through participants and inductively analyzed and interpreted by the researcher.

The next step in this research was to transcribe the data collected from semi-structured interviews. The researcher focused on the difficulties that are faced by the participants. The participants for this study were L2 teachers teaching at private secondary schools of Hyderabad, Pakistan. Braun and Clark (2006) model of thematic analysis were used to analyze the interview data.

\subsection{Sampling and participants of the study}

The current study opted for purposive sampling. Purposeful sampling is used in qualitative research to locate and select information-rich situations in order to make the best use of limited resources (Patton, 2002). The participants for this study are 5 in-service EFL teachers teaching at private secondary schools.

\subsection{Data collection and analysis}

The data collection process includes semi-structured interviews and classroom observation. The participants were the teachers teaching English at secondary classes at private schools of Hyderabad. Also, the classes of 2 participants were observed during first step of data collection. 5 out of 3 participants were interviewed in order to find the detailed challenges faced by teachers in implementation of learner-centered approach. The collected data was analyzed through Braun and Clark's thematic model (2006). The researcher became familiarized with the data then generated the themes after the codes were made. The themes' authenticity and dependability were verified. The themes were explicitly defined and labelled, and the findings were given after the data had been interpreted.

\section{Findings and Discussion}

The findings according to 3 participants suggests that they find it difficult to implement this approach because they are instructed by the school administration prior to the lectures because it is not in their hands to design the lesson plan in their way. Teachers also said that the number of students in a single class are huge that it makes even more difficult for them to teach them through this approach. The environment of schools is not much favorable for teachers where they could use learner-centered approach. This is in line with Olana and Amante (2017), they maintained that teachers do not have access to a conducive atmosphere in which they used learnercentered approach in their classes.

As teachers confessed that they are already guided by school administration to which methodology they should use in classroom. Their main focus is to complete the course rather than to improve learning process of the students. A research study was conducted by Bremmer (2019), in which he found out that all his participants were motivated and were in favor of using learner-centered approach but there were restrictions drawn by their institutes.

Other factor that effects the most in implementation of this approach is large classes. As Sarwar (2001) viewed that in Pakistan, number of pupils in a single class is huge that it made nearly impossible to pay attention to every single student. Because of the huge classes, backbenchers are always avoided. Teacher becomes unable to listen to them as other students keep on talking. 
Limited time that is also one of the most effecting factors in classrooms. As Harju and Akerblom (2017), stated that teacher prefer lecture method because it covers the topic within the given time as their only focus is to finish the course content. On other hand, it is also about the beliefs of teahcers toward learner-centered approach. Some says that it consumes a lot of time, teacher has to work more and had to fulfill the learning needs of every student. One participant responded that it is very difficult to teacher language skills to the class in which 50\% students are motivated and $50 \%$ are demotivated that is why my classes are mostly teacher centered. Learners are used to of teacher-centered approach that is why they are do not pay attention when they are taught with leaner-centered approach in EFL classes. They lack confidence, waste their time in other activities and disturbs the whole class.

The classroom observations revealed that teachers are unable to teach with learner-centered approach because there are huge number pf students, class is overpopulated, the size of class is also not allowing teachers to assess every learner individually because individual assessment in the classroom needs a space where a teacher can move to back benchers too. Teachers were paying attention to the students who were engaged with them through out the class. Furthermore, the classroom's infrastructure is also not favorable for teachers because of less space of walking where teacher can move to see every student's progress when they are giving a group task to them. There was also unavailability of resources such as, audio/visual materials where they could improve their language learning by watching videos and listening to the audio tapes. So, it becomes difficult for teachers to achieve their target objectives when the classroom conditions are unsatisfactory (O'Sullivan, 2002; Bantwini, 2010).

\section{Conclusion}

This study found that difficulties that teacher faced in implementation of learner-centered approach in EFL classrooms at private secondary schools of Hyderabad Pakistan. According to the literature review, the difficulties in the implementation are nearly least researched in English subject in the context of Pakistan. However, its positive effects are researched in detailed in Pakistani context. The study reveals that there is nearly no solution is entertained to address the issues in its implementation. Teacher's training is also less provided to the teachers. even if they are given trainings, but still, they cannot apply them in their classes. Teachers who are motivated to teach with learner-centered approach, their beliefs fluctuates when they reach in the class (An Reigeluth,2011)

In Pakistan, education is more challenging because of many issues but the most common is lack of educational fundings. School funding issues are still a problem. While the economy has rebounded since the Great Recession, school budgets have not. Budget cuts are still being made across the board, class sizes are growing, and pre-kindergarten programs are being phased out, resulting in less learning time. (Akhtar et al. 2018).

Financial constraints limit teacher training facilities, and they are ill-equipped to meet the demands of today's teacher education system. Services such as teaching aids, buildings, libraries, furniture, text materials, and other related tools are in short supply at teacher training institutes. The examination system at these institutes is inadequate, and teacher absenteeism, poor management, and inefficient administration are further exacerbated issues (Farah, Fauzee \& Daud, 2016).

\section{References}

Akhter, N., Din, M. N. U., \& Khan, A. M. (2018). The Mathematics Elementary School Teachers' Perceptions of the Student-Centered Approaches and Professional Learning Experiences. Global Social Sciences Review, 3(4), 87-101.

An, Y. J., \& Reigeluth, C. (2011). Creating Technology-Enhanced, Learner-Centered Classrooms: K-12 Teachers' Beliefs, Perceptions, Barriers, and Support Needs. Journal of Digital Learning in Teacher Education, 28(2), 54-62. https://doi.org/10.1080/21532974.2011.10784681

Azam, F., Omar Fauzee, M. S., \& Daud, Y. (2014). Teacher training education programme in three Muslim countries Afghanistan, Iran and Pakistan. Journal of Education and Human Development, 3(2), 729-741.

Bremner, N. (2019). From learner-centred to learning-centred: Becoming a 'hybrid' practitioner. International Journal of Educational Research, 97(April), 53-64. https://doi.org/10.1016/j.ijer.2019.06.012.

Denzin, N. K., \& Lincoln, Y. S. (Eds.). (2011). The Sage handbook of qualitative research. sage. 
Du Plessis, E. (2020). Student teachers' perceptions, experiences, and challenges regarding learner-centered teaching. South African Journal of Education, 40(1).

Harju, A., \& Akerblom, A. (2017). Colliding collaboration in student-centered learning in higher education. Studies in Higher Education, 42(8), 1532-1544.

Hoidn, S. (2016). Student-centered learning environments in higher education classrooms. Springer.

Mazer, J. P., \& Hess, J. A. (2017). What is the place of lecture in higher education? Communication Education, 66(2), 236-237.

Mina, S. and Zohreh, S. (2015). “Iranian English Teachers' Beliefs about Teacher-centered

Education vs. Their Beliefs about Actual Classroom Roles.” DU Journal, Humanities and

Social Sciences, 8 (5): 471-484.

Olana, E., \& Amante, T (2017). Factors Affecting Implementation of Student-Centered Learning methods.

Patton, M. Q. (2002). Qualitative research and evaluation methods. Thousand Oaks. Cal.: Sage Publications, 4.

Sarwar, Z. (2001). Adapting individualization techniques for large classes. Innovation in English language teaching: A reader, 127-136.

Tani, M. (2005, January). Quiet, but only in class: Reviewing the in-class participation of Asian students. In Higher Education Research and Development Society of Australia Conference, Sydney, New South Wales. Retrieved September (Vol. 5, p. 2007).

Tadesse, A., Eskelä-Haapanen, S., Posti-Ahokas, H., \& Lehesvuori, S. (2021). Eritrean teachers' perceptions of learner-centered interactive pedagogy. Learning, Culture and Social Interaction, 28, 100451. 